\title{
An Approach for the Estimation of Hydrometeorological Variables Towards the Determination of Z-R Coefficients
}

\author{
E. A Baltas ${ }^{1}$ - D. S. Panagos ${ }^{1}$ - M. A. Mimikou ${ }^{1}$
}

Received: 26 August 2015 / Accepted: 28 October 2015 /Published online: 11 November 2015

(C) Springer International Publishing Switzerland 2015

\begin{abstract}
An attempt is made to estimate the basic hydrometeorological variables, namely the rainfall concentration for each bin per $\mathrm{m}^{3}$, the radar reflectivity factor $\mathrm{Z}$ and the rainfall intensity $\mathrm{R}$, and consequently to determine coefficient "a" and exponent " $\mathrm{b}$ " of the power law relationship $\mathrm{Z}=\mathrm{aR}^{\mathrm{b}}$. Data used were recorded in a period of almost 10 years, with a JossWalvogel RD-69 disdrometer (JWD), located in the meteorological station of the campus of National Technical University of Athens. A number of rainfall events were selected based on the following criteria: the total rainfall depth of each event was greater than $24.0 \mathrm{~mm}$ and the average rainfall intensity exceeded $5.0 \mathrm{~mm} / \mathrm{h}$, in order to only study events with increased flash flooding probability. Initially, Drop Size Distributions (DSDs) were calculated for these rainfall events and processed for the derivation of Z-R relationships. Such Z-R relationships were finally derived for the overall spectra of $R>5.0 \mathrm{~mm} / \mathrm{h}$ and for each event separately and were compared with other Z-R relationships found in the literature.
\end{abstract}

Keywords JWD $\cdot$ Disdrometer $\cdot$ Radar reflectivity $\cdot$ Rainfall $\cdot Z$-R relationships

\section{Introduction}

The general metropolitan area of Athens, in Attica Greece is inhabited by more than 4.0 million residents and spans over $430 \mathrm{~km}^{2}$. Athens is surrounded by three mountains, namely Parnitha, Penteli and Imittos. This geomorphological setup is responsible for a low annual rainfall depth, but also for seasonal temperature and wind instabilities. Furthermore, manmade constructions in Athens have minimized the water retention capacity of the physical terrain and have increased significantly the runoff coefficient, resulting in the subsequent increase of flood-prone areas. Convective rainfall events in Athens often cause flash floods with disastrous

E. A Baltas

baltas@chi.civil.ntua.gr

1 Department of Water Resources, Hydraulic and Maritime Engineering, National Technical University of Athens, 5 Iroon Polytechniou, Zografou, 15780 Athens, Greece 
consequences on the environment and the economy, and in some cases, they have resulted in loss of lives (Korologou et al. 2014).

In order to monitor the meteorological and hydrological properties of the area, the Department of Water Resources, Hydraulic and Maritime Engineering, School of Civil Engineering, National Technical University of Athens (NTUA), has installed a network of meteorological and flow measurement stations, and a Joss-Walvogel RD-69 disdrometer (JWD). The official site of the network, which is called Hydrological Observatory of Athens (HOA) (Fig. 1), can be found in www.hoa.ntua.gr. This site contains various timeseries of meteorological variables of raw and processed data which are freely available. Various calculated indicators, statistical data, weather highlights, rainfall event reports etc., are also available. The JWD has been installed on the campus of NTUA and operates since 1997. The coordinates of the station are in WGS84: 37.9798, 23.7796, 181.0.

A recently acquired $\mathrm{x}$-band meteorological radar, which is currently on calibration phase, is planned to be installed and incorporated into HOA. The aforementioned meteorological $\mathrm{x}-$ band radar will help in the direction of mitigating the impacts of a flash flood in Athens area, given the fact that it will be used as a nowcasting tool. Nevertheless in order to have a reliable warning system, accurate quantitative precipitation estimates (QPEs) are needed. These QPEs are a result of the reliable conversion of the radar reflectivity $\mathrm{Z}$ into rainfall intensity $\mathrm{R}$ taking into advantage its power law relationship: $Z=\mathrm{aR}^{\mathrm{b}}$. Unfortunately, many factors influence the coefficients "a" and " $b$ " of this relationship. They are categorized in climatological factors such as rainfall type (convective vs. stratiform rainfall) or the bright band phenomenon

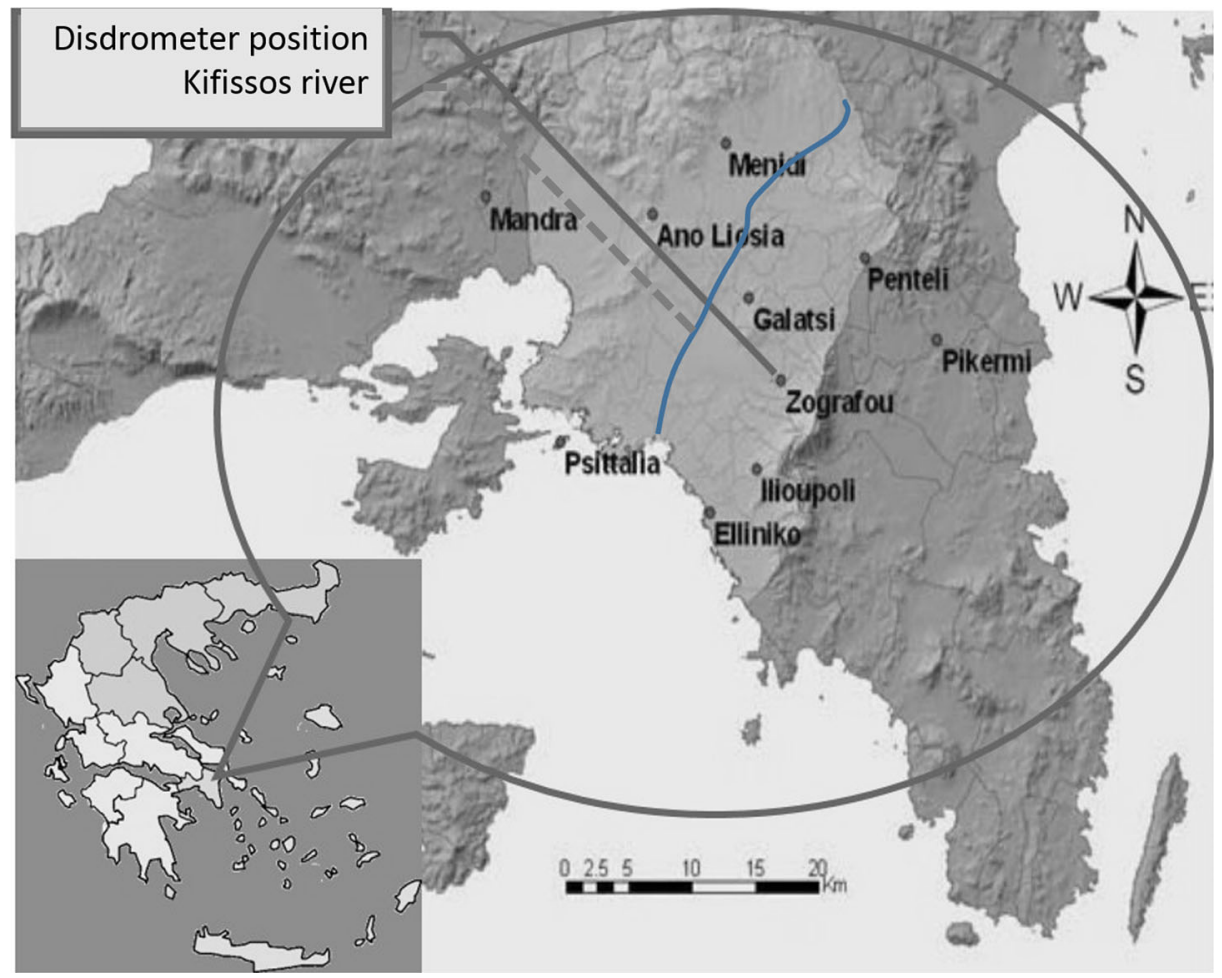

Fig. 1 Locations of meteorological stations and of the RD-69 disdrometer 
(Brandes et al. 2004), physical factors such as meteorological conditions, as well as, instrumental factors, like calibration errors and inherent instrument deficiencies (Uijlenhoet et al. 2006). Meteorological factors include variations of temperature, barometric pressure and wind speed, as well as cloud updrafts or downdrafts which are involved in micro-scale rainfall generation processes (Tokey and Short 1996).

The aim of the current study is the identification of the proper Z-R relationship (or a set of relationships) for radar operational use during flash floods, utilizing DSD measurements collected from the JWD. This task is quite challenging, due to the spatial and temporal variability of Z-R relationships among various events, or even during the same event. Given the importance of rainfall estimation through radar reflectivity measurements, a substantial number of researchers have contributed in this field; to name a few, Marshall and Palmer (1948) established the analysis of Drop Size Distributions (DSDs) for meteorological radar studies, Sempere-Tores et al. (2000) investigated DSDs and Z-R relationships, under a convective vs. stratiform approach, Baltas and Mimikou (2002) investigated a Z-R relationship for an extreme event that occurred over Athens in 1999. Finally, Tenorio and Kwon (2006) estimated Z-R relationships in Brazil, Hazenberg et al. (2011) investigated Z-R relationships in France, and Nzeukou et al. (2004) studied Z-R relationships in north-west Africa.

\section{Methodology}

For the investigation of Z-R relationships, recorded data from a JWD have been analyzed and processed with the method of linear regression, and event-based Z-R relationships have been derived. The archived dataset includes approximately 90.000 1-min spectra of rainfall. The JWD is uninstalled for almost 2 months in the summer period for the protection of its impact cone, so measurements during the summer months are not available. The main effort of this study was to isolate convective events with high flooding probability and to investigate their internal rainfall properties through the respective DSDs and estimated Z-R relationships. These events seem to deviate substantially in the "a" and " $b$ " coefficients from the coefficients of the stratiform events. This is probably due to considerable spatiotemporal gradients that make the correct estimation of the amount of precipitation during convective events very important and challenging (Hazenberg et al. 2011).

Taken into account that convective events are characterized by local scale deployment, usually less than $50 \mathrm{~km}^{2}$, it can be realized that only a fraction of the actual events was able to be measured by the disdrometer. For example, a major convective event occurred in Athens metropolitan area on 24 October 2014. The center of this rainfall event was about $25 \mathrm{~km}$ northwest from the site of the disdrometer (between Ano Liosia and Menidi municipalities; Fig. 1). Local streams overflowed causing great economic loss. In less than $6 \mathrm{~h}$, more than $77 \mathrm{~mm}$ of rainfall were gauged at the meteorological station of Ano Liosia, while Menidi station recorded $69 \mathrm{~mm}$. On the contrary, Zografou station (Fig. 1) recorded only $17 \mathrm{~mm}$ for the same event. Nevertheless, Zografou station is sited in a densely populated area and its measurements have increased importance as far as flood studies are concerned.

Initially in order to aggregate the total sample of 90,000 1 min spectra of rainfall data, in discrete rainfall events, a no-rain time interval of $6 \mathrm{~h}$ was considered. The reason is that steep slopes, generally characterizing the region of Attica, plus urbanization, have resulted in the decrease of the time of concentration $T_{c}$, at the outlet of the main basin of Athens, that of the 
Kifissos river (Fig. 1), to lower than $6 \mathrm{~h}$. Considering a $6 \mathrm{~h}$ no-rain time interval for the identification of discrete rainfall events is a pro-safety assumption in comparison with smaller no-rain intervals (i.e., $3 \mathrm{~h}$ ). For instance, if there is an actual no-rain interval of $4 \mathrm{~h}$, if the time interval of $6 \mathrm{~h}$ criterion is adopted, the whole rainfall is considered as a single event, but in the case when a time interval of $3 \mathrm{~h}$ is adopted, then two separate events are assumed. So, in the latter case, the combining flooding action of the assumed separate events will not be taken into account, even though there is a chance that the two produced hydrographs will contribute simultaneously in the river discharge.

For the distinction of events with increased flooding probability against events with lower flooding probability, the combination of two criteria was adopted: the total rainfall depth RD, and the mean rainfall intensity RI. The total rainfall depth plays a significant role in flash floods, since if multiplied by the area, it will produce the total volume of rainwater that will be actually precipitated. After consideration, a threshold for rainfall depth $\mathrm{RD}>24 \mathrm{~mm}$ was selected, which represents the upper $10 \%$ percentile in terms of total rainfall depth, recorded by the JWD in the studied dataset.

The rainfall depth criterion does not necessarily end up in a flash flood, as runoff is strongly dependent on soil moisture antecedent conditions, apart from other factors. In order to better approximate the flash flooding potential of a rainfall event, it is necessary to impose an additional criterion besides the rainfall depth; this criterion is rainfall intensity. The reason is that in stratiform type of precipitation, occasionally, large volume of water is precipitated over a span of many hours. This actually will not lead to a flash flood because the rate of water volume ending into the urban storm sewer system is lower than the system capacity, so eventually does not cause an overflow, assuming that the network is well maintained and sewer blockages are minimized. Taking into account these facts, a rainfall intensity threshold of $\mathrm{R}>$ $5.0 \mathrm{~mm} / \mathrm{h}$ was adopted. This threshold represents the upper $11 \%$ percentile in terms of mean rainfall intensity for the entire JWD dataset. It has to be underlined that under the current study the aim is not exactly to distinguish convective and stratiform events, but to isolate the most probable flood prone events of the available dataset.

After the selection of the events according to the pre-mentioned criteria, the next step was the construction of the Z-R relationships. The well-known analysis of the rainfall DSDs measured by the JWD was followed. DSDs are an expression of drops per cubic meter per millimeter bin interval $\left(\mathrm{m}^{-3} \mathrm{~mm}^{-1}\right)$ and are used to obtain the rainfall concentration for each bin in $\mathrm{m}^{-3}$ by multiplying the original DSD by the respective bin width (Martins et al. 2010). Then, the total concentration and the rainfall intensity $\mathrm{RI}$ in $\mathrm{mm} / \mathrm{h}$ can also be determined by proper transformations (the size of the impact cone area of the JWD is $50 \mathrm{~cm}^{2}$ ).

The rainfall concentration $\mathrm{N}\left(\mathrm{D}_{\mathrm{i}}\right)$ for each bin in $\mathrm{m}^{-3}$ is calculated by the following equation:

$$
N\left(D_{i}\right)=\frac{N_{A}\left(D_{i}\right)}{A t V\left(D_{i}\right) \Delta D i}
$$

where:

$\mathrm{N}_{A}\left(\mathrm{D}_{\mathrm{i}}\right)$ the number of raindrop hits for each bin of diameter

A the surface of the impact cone in $\mathrm{m}^{2}$

$\mathrm{t}$ the time interval of recording in $\mathrm{s}$ 
$\mathrm{V}\left(\mathrm{D}_{\mathrm{i}}\right) \quad$ the terminal velocity of drops in $\mathrm{m} / \mathrm{s}$

$\Delta \mathrm{D}_{\mathrm{i}} \quad$ the diameter interval of each bin in $\mathrm{mm}$

The rainfall intensity $\mathrm{RI}$ in $\mathrm{mm} / \mathrm{s}$ is then calculated by the following expression (Harikumar et al. 2009):

$$
R=\frac{3.6 \pi}{6 \cdot 10^{3}} \int_{0}^{\infty} N\left(D_{i}\right) D_{i}{ }^{3} V\left(D_{i}\right) \Delta D_{i}
$$

where:

$\mathrm{N}\left(\mathrm{D}_{\mathrm{i}}\right)$ the rainfall concentration for each bin in $\mathrm{m}^{-3}$ with units $\mathrm{m}^{-3} \mathrm{~mm}^{-1}$

$\mathrm{D}_{\mathrm{i}} \quad$ the average drop diameter for each bin in $\mathrm{mm}$

The radar reflectivity $\mathrm{Z}$ is calculated by the expression:

$$
Z=\sum_{i=1}^{20} N\left(D_{i}\right) D_{i}^{6} \Delta D_{i}
$$

where all parameters have been defined previously.

For the estimation of terminal velocity, the empirical expression proposed by Atlas and Ulbrich (1977) has been adopted $\left(\mathrm{V}_{\mathrm{t}}\right.$ in $\mathrm{m} / \mathrm{s}$ and $\left.0.05<\mathrm{D}<0.5 \mathrm{~cm}\right)$ :

$$
V_{t}=17.67 D^{0.67}
$$

Uncertainty is introduced since there is not one-to-one correspondence between terminal velocity and apparent drop size (Krajewski et al. 2006). Nevertheless, this expression was adopted, since it overestimates the terminal velocity, in the larger diameter spectrum, in relation to other terminal velocity expressions, partially counterweighting the dead-time error of the instrument in intense rainfall. The dead-time error occurs when a large drop hits the instrument and as a result the instrument misses some drops for a small time interval afterwards, due to the time needed for the impact cone to return to the initial position (Brawn and Upton 2008).

After the calculation of $\mathrm{Z}$ and $\mathrm{R}$ values for each event, the $\mathrm{Z}-\mathrm{R}$ relationship is estimated with the method of linear regression. Z-R relationship follows the aforementioned power law:

$$
\mathrm{Z}=\mathrm{a} \mathrm{R} \mathrm{R}^{\mathrm{b}}
$$

By applying logarithms in both parts of Eq. (5), this equation is transformed into a linear equation of the type:

$$
\log Z=\log a+b \log R
$$

where coefficients "a" and "b" can be estimated.

\section{Results}

Applying the methodology described in the previous section, after taking into account the $6 \mathrm{~h}$ no-rain interval between rainfall events, four hundred fifty seven (457) rainfall events were identified. The combination of the criteria of rainfall intensity and total rainfall depth resulted 
Table 1 Selected rainfall events

\begin{tabular}{llllclll}
\hline No & Date & Event duration (min) & Rainfall Depth (mm) & Rainfall intensity $(\mathrm{mm} / \mathrm{h})$ & $\mathrm{a}$ & $\mathrm{b}$ & $\mathrm{R}^{2}$ \\
\hline 1 & $2 / 5 / 2006$ & 642 & 54.93 & 5.13 & 397 & 1.41 & 0.979 \\
2 & $10 / 21 / 2007$ & 510 & 45.23 & 5.32 & 278 & 1.42 & 0.967 \\
3 & $3 / 18 / 2009$ & 206 & 27.89 & 8.12 & 217 & 1.44 & 0.961 \\
4 & $10 / 18 / 2010$ & 296 & 25.95 & 5.26 & 279 & 1.43 & 0.933 \\
5 & $6 / 12 / 2011$ & 148 & 41.12 & 16.67 & 455 & 1.44 & 0.976 \\
6 & $2 / 6 / 2012$ & 534 & 54.53 & 6.13 & 349 & 1.36 & 0.972 \\
7 & $11 / 29 / 2012$ & 328 & 36.10 & 6.60 & 281 & 1.49 & 0.955 \\
8 & $1 / 16 / 2013$ & 164 & 33.64 & 12.31 & 316 & 1.52 & 0.914 \\
9 & $2 / 22 / 2013$ & 364 & 68.13 & 11.23 & 390 & 1.48 & 0.963 \\
10 & $11 / 11 / 2013$ & 258 & 25.85 & 6.01 & 412 & 1.39 & 0.973 \\
11 & $1 / 25 / 2014$ & 148 & 24.81 & 10.06 & 300 & 1.41 & 0.979 \\
\hline
\end{tabular}

in the separation of 11 rainfall events out of the 457 events. These events are presented in Table 1. Also in Table 1 the coefficients "a" and "b", of Eq. (5) have been estimated, together with the respective coefficient of determination $R^{2}$ of the regression analysis. The values $R^{2}$ are high in all events, showing a very good correlation.

A characteristic event of 22 February 2013, with $68.13 \mathrm{~mm}$ of total rainfall depth, is seen in Fig. 2.

This particular event caused major flooding problems in the area of Pikermi, on the east of Attica (Fig. 1), where local streams overflowed and inundated houses, industrial units and crop lands. It has to be mentioned again that not all flooding events over Athens region were included in this analysis because JWD is placed in Zografou station and only events recorded by the particular instrument were able to be studied.



Fig. 2 Z-R relationship of the 22 February 2013 rainfall event 


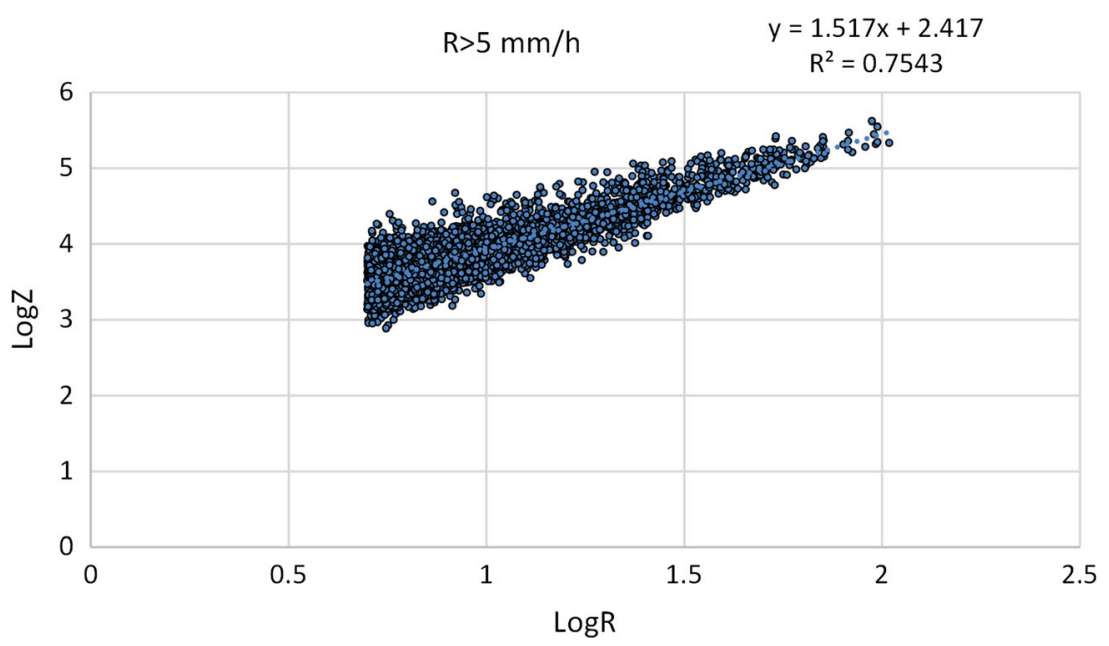

Fig. 3 Overall Z-R relationship, considering rainfall intensity $\mathrm{R}>5.0 \mathrm{~mm} / \mathrm{h}$

Regarding coefficient "a", Table 1 shows a high variability in values. Values range from a minimum of 217 to a maximum of 455 . If the total sample of 457 rainfall events is used for deriving an overall Z-R relationship, excluding values of rainfall intensity smaller than $5 \mathrm{~mm} /$ $\mathrm{h}$, then the overall expression of $\mathrm{Z}=261 \mathrm{R}^{1.52}$ is derived, as shown in Fig. 3. This expression is similar to the expression derived in Ferrara Italy by Caracciolo et al. (2008), which is $Z=$ $273 \mathrm{R}^{1.48}$. Uijlenhoet et al. (2003) proposed the relationship $Z=277 \mathrm{R}^{1.48}$ which is very close to the estimated one in this study. It should be underlined that the coefficient " $\mathrm{a}$ " is determined by the shape of the general drop size distribution and in particular from its sixth moment (the radar reflectivity), so larger values of "a" are proportionate to larger reflectivity values which are produced by DSDs with more counts on the upper diameters, regarding the same rainfall intensity. This fact denotes that when rainfall events are closer to the convective type, where the drops are larger compared to the stratiform type, the coefficient "a" will have larger values.

Baltas and Mimikou (2002) suggested the relationship $Z=408 \mathrm{R}^{1.26}$ for an extreme convective type event, with $89 \mathrm{~mm}$ total rainfall depth and an estimated 25 years return period, that occurred in the Athens area on 20 November 1999. Events, like the aforementioned are usually associated with larger raindrop size concentrations and larger vertical extents (Hazenberg et al. 2011).

However, it should be noted that the findings of this research come in contradiction with convective rainfall events in tropical climates giving convective rainfall Z-R relationships of the type $Z=65 R^{1.69}$ (Tenorio and Kwon 2006). This can be attributed to the differences in typical Mediterranean climate and the tropical one.

Table 2 Various Z-R relationships

\begin{tabular}{llll}
\hline Study & Region & Coefficient “a” & Exponent "b" \\
\hline Current research & Athens, Greece & 261 & 1.52 \\
Caracciolo et al. (2008) & Ferrara, Italy & 273 & 1.48 \\
Uijlenhoet et al. (2003) & USA & 277 & 1.48 \\
Tenorio and Kwon (2006) & Brazil & 65 & 1.69 \\
\hline
\end{tabular}


Coefficient "b" presents a more predictable range of values, with lower limit of 1.36 and upper 1.52 for all eleven events. In the overall Z-R relationship for $\mathrm{R}>5 \mathrm{~mm} / \mathrm{h}$, coefficient " $\mathrm{b}$ " has the value 1.52, which corresponds to the upper limit of the eleven selected events. In Table 2 some Z$\mathrm{R}$ relationships referred to in this analysis are presented for comparison reasons.

\section{Conclusions and Recommendations}

Four hundred fifty seven rainfall events have been recorded by a Joss-Waldvogel RD-69 disdrometer (JWD) since October 2005 forming a dataset of 90,000 1 min spectra of rainfall. After a filtering procedure using a set of specific criteria, eleven rainfall events have been isolated and analyzed in the present research work. The criteria for the selection of the events were their increased flood probability over the region of Attica Greece, where the city of Athens is located. Under this aspect, events with total rainfall depth of more than $24 \mathrm{~mm}$ were selected and with more than $5 \mathrm{~mm} / \mathrm{h}$ mean rainfall intensity. Discrete rainfall events were separated using the criterion that the time of concentration at the outlet of the main river basin in Attica, Kifissos river, is less than $6 \mathrm{~h}$, so no-rain time intervals of $6 \mathrm{~h}$ would result in independent runoff hydrographs for the assumed rainfall events.

This research was focused on the derivation of hydrometeorological parameters of rainfall and more specifically on Z-R relationships. The results led to the overall relationship $Z=$ $261 \mathrm{R}^{1.52}$ for $\mathrm{R}>5 \mathrm{~mm} / \mathrm{h}$. Also "a" and " $\mathrm{b}$ " coefficients of the power law Z-R relationship have been derived for each selected rainfall event. The analysis showed that the coefficients " $\mathrm{a}$ " and "b" of the overall Z-R convective relationship are similar with derived ones on the Mediterranean climate zone, but not with the ones derived in other climate zones. Following the event-based analysis, coefficient "a" of the Z-R relationship was estimated between 200 and 450, with more prevailing range between 300 and 350, while exponent "b" was estimated between 1.36 and 1.52 , but usually ranging between 1.40 and 1.44 . The internal mechanism of rainfall production, and more specifically convective or stratiform type of rainfall, influence the shape of DSDs resulting in unique Z-R relationships. Further research is needed in the direction of better understanding the micro-scale nature of rainfall production and precipitation. Also, the Z-R relationship should be further analyzed based on the type of precipitation, including the uncertainty of the coefficients.

\section{References}

Atlas D, Ulbrich CW (1977) Path and area integrated rainfall measurement by microwave attenuation in the 1$3 \mathrm{~cm}$ band. J Appl Meteorol 16:1322-1331

Baltas EA, Mimikou MA (2002) The use of a Joss-type disdrometer for the derivation of Z-R relationships. In: Second European conference on radar in meteorology and hydrology (ERAD 2002), Delft, Netherlands, 291-294

Brandes EA, Zhang G, Vivekanandan J (2004) Drop size distribution retrieval with polarimetric radar: model and application. J Appl Meteorol 43:461-475

Brawn D, Upton G (2008) Estimation of an atmospheric gamma drop size distribution using disdrometer data. Atmos Res 87:66-79. doi:10.1016/j.atmosres.2007.07.006

Caracciolo C, Porcu F, Prodi F (2008) Precipitation classification at mid-latitudes in terms of drop size distribution parameters. Adv Geosci 16:11-17

Harikumar R, Sampath S, Sasi Kumar V (2009) An empirical model for the variation of rain drop size distribution with rain rate at a few locations in southern India. Adv Space Res 43:837-844. doi:10.1016/j. asr.2008.11.001 
Hazenberg P, Yu N, Boudevillain B, Delrieu G, Uijlenhoet R (2011) Scaling of raindrop size distributions and classification of radar reflectivity-rain rate relations in intense Mediterranean precipitation. J Hydrol 402: 179-192. doi:10.1016/j.jhydrol.2011.01.015

Korologou M, Flocas H, Michalopoulou H (2014) Developing an index for heavy convective rainfall forecasting over a Mediterranean coastal area. Nat Hazards Earth Syst Sci 14:2205-2214. doi:10.5194/nhess-14-22052014

Krajewski WF et al (2006) DEVEX-disdrometer evaluation experiment: basic results and implications for hydrologic studies. Adv Water Resour 29:311-325. doi:10.1016/j.advwatres.2005.03.018

Marshall JS, Palmer WM (1948) The distribution of raindrops with size. J Meteorol 5:165-166

Martins RCG, Machado LAT, Costa AA (2010) Characterization of the microphysics of precipitation over amazon region using radar and disdrometer data. Atmos Res 96:388-394. doi:10.1016/j.atmosres.2010.01. 011

Nzeukou A, Sauvageot H, Ochou AD, Kebe CMF (2004) Raindrop size distribution and radar parameters at Cape Verde. J Appl Meteorol 43:90-105

Sempere-Tores D, Sanchez-Diezma R, Zawadzki I, Creutin JD (2000) Identification of stratiform and convective areas using radar data with application to the improvement of DSD analysis and Z-R relations. Phys Chem Earth 25:985-990

Tenorio RS, Kwon BH (2006) Z-R relationship and a severe rainfall observed by C-band radar in eastern coast of northeastern Brazil. In: Forth European conference on radar in meteorology and hydrology (ERAD), Barcelona, Spain

Tokey A, Short AD (1996) Evidence from tropical raindrop spectra of the origin of rain from stratiform versus convective clouds. J Appl Meteorol Climatol 35:355-370

Uijlenhoet R, Steiner M, Smith JA (2003) Variability of raindrop size distributions in a squall line and implications for radar rainfall estimation. J Hydrometeorol 4:43-61

Uijlenhoet R, Porrà JM, Torres DS, Creutin J-D (2006) Analytical solutions to sampling effects in drop size distribution measurements during stationary rainfall: estimation of bulk rainfall variables. J Hydrol 328:6582. doi:10.1016/j.jhydrol.2005.11.043 